\title{
Microencapsulation of Sodium Hydrogen Carbonate to Generate Carbon Dioxide with Thermal Responsible Shell Material
}

\author{
Yohei Koyama', Natsukaze Saito', Kiyomi Fuchigami², Yoshinari Taguchi', \\ Masato Tanaka ${ }^{*}$ \\ ${ }^{1}$ Graduate School of Science and Technology, Niigata University, Niigata, Japan \\ ${ }^{2}$ Department of Research \& Development, Shofu Inc., Kyoto, Japan \\ Email: "tanaka@eng.niigata-u.ac.jp
}

Received 23 February 2015; accepted 15 March 2015; published 17 March 2015

Copyright (C) 2015 by authors and Scientific Research Publishing Inc.

This work is licensed under the Creative Commons Attribution International License (CC BY). http://creativecommons.org/licenses/by/4.0/

(c) (i)

\begin{abstract}
This paper tried to develop the optimum procedure for microencapsulating water soluble solid powder with the thermal responsible material by the melting dispersion cooling method. Sodium hydrogen carbonate was adopted as a water soluble solid powder instead of microencapsulating carbon dioxide gas. The shell material was composed of olefin wax and $\alpha$-tocopherol. In the experiment, the concentration of oil soluble surfactant and the water soluble surfactant species were changed. Sodium hydrogen carbonate was treated in the aqueous solution dissolving the water soluble surfactant to form the finer sodium hydrogen carbonate powder and to increase the content. The microencapsulation efficiency could be increased with the concentration of oil soluble surfactant and considerably increased by treating sodium hydrogen carbonate with the water soluble surfactant. Sodium hydrogen carbonate was protected well from environmental water. The microcapsules showed the thermal responsibility to generate carbon dioxide.
\end{abstract}

\section{Keywords}

Thermal Responsible Microcapsules, Melting Dispersion Cooling Method, Sodium Hydrogen Carbonate, Olefin Wax, $\alpha$-Tocopherol

\section{Introduction}

As the microcapsules which can contain the core materials such as gas, liquid and solid have the various functions, many kinds of microcapsules have been prepared and applied in the various fields such as latent heat sto-

\footnotetext{
${ }^{*}$ Corresponding author.
}

How to cite this paper: Koyama, Y., Saito, N., Fuchigami, K., Taguchi, Y. and Tanaka, M. (2015) Microencapsulation of Sodium Hydrogen Carbonate to Generate Carbon Dioxide with Thermal Responsible Shell Material. Journal of Cosmetics, Dermatological Sciences and Applications, 5, 36-44. http://dx.doi.org/10.4236/jcdsa.2015.51005 
rage, cosmetics, food, drugs, paintings, adhesives, textile, and electric materials [1]-[3]. The important functions of microcapsules are to protect the core materials from environment for a long time, to optionally release the core materials according to stimuli, to modify the surface of core material and to change the core materials such as liquid and gas to the particulate core materials [1]-[3]. The microcapsules with these functions can be prepared by selecting the core and the shell materials with the desired chemical and physicochemical properties and by developing the microencapsulation procedure. In general, in order to microencapsulate the water soluble core materials, the hydrophobic shell materials are used to increase the content and to protect the core from water or moisture by the help of oil soluble surfactant [4]-[7]. Also, the non aqueous solvents as the continuous phase have been sometimes used to prevent the core from leaking way during the microencapsulating process [8] [9]. Meanwhile, on applying the microcapsules to food, cosmetics, drugs and textile, the nontoxic materials have to be used as the shell material. For example, the chemical preparation methods using polymezable monomers such styrene and acryl monomer cannot be used. In this case, the physicochemical preparation methods and the chemical methods using the nontoxic materials may be recommended [10] [11].

It is well known that it is very hard to microencapsulate the gaseous materials and perfectly prevent them from leaking for a long time. In this case, it may be effective to microencapsulate solid powders generating the desired gas instead of microencapsulating gas. Namely, if solid powder could be microencapsulated with some stimuli responsible shell materials, gas could be generated by breaking the shell due to suitable stimuli and by dissolving solid powder into the some solvent. Thus, as solid powder can be relatively easily microencapsulated and protected stably for a long time, the desired gas may be generated as occasion demands. However, it is necessary to newly develop the microencapsulation procedure in order to stably microencapsulate solid powder and to protect solid powder from environment according to the physicochemical properties of solid powder species.

Taking these things described above into consideration, we tried to microencapsulate sodium hydrogen carbonate as a water soluble solid powder instead of microencapsulating carbon dioxide gas.

Sodium hydrogen carbonate is dissolved well in the acid solution, generated carbon dioxide and changed from the acid solution to the alkaline solution. If sodium hydrogen carbonate powder could be stably microencapsulated with the thermal responsible shell material, carbon dioxide gas with a few physicological effects [12] [13] could be generated by breaking down the microcapsules due to heating and by contacting solid powder with the optimum aqueous solution. If the microcapsules thus prepared were used in the cosmetic materials such as the face cream and the basic skin care powder, carbon dioxide gas could be supplied to the face.

In the case of preparing the microcapsules containing the water soluble solid powders as sodium hydrogen carbonate, it may be desirable that the hydrophobic shell materials are used and yet the microencapsulation procedure with the shorter processing time is applied.

In this study, it was tried to microencapsulate sodium hydrogen carbonate with the hydrophobic shell material by using the melting dispersion cooling method in the oil-in-water emulsion. The purposes of this study are to develop the optimum preparation conditions for preparing the microcapsules, to characterize the microcapsules and to investigate whether carbon dioxide gas could be generated by breaking the microcapsules due to heating or not.

\section{Experimental}

\subsection{Materials}

Materials used to prepare the microcapsules were as follows. The shell material was olefin wax (CPAO: Idemitsu Kosan, Co., Ltd., Japan) with the melting point of $40^{\circ} \mathrm{C}$. The additives added to modify the shell material were $\alpha$-tocopherol (VE) and the oil soluble surfactant. Sodium hydrogen carbonate (SHC) was adopted as the model water soluble solid powder. The oil soluble surfactant was polygricerine polyricinorate (Poem PR-300) and the water soluble surfactants were decaglycerin monolaurate (J-0021) and diglycerin monolaurate (DL-100). Glycerin was used as the continuous phase instead of water. The chemicals stated above were from Wako Pure chemicals Co., Ltd., Tokyo, Japan.

\subsection{Preparation of Microcapsules}

Figure 1 shows the flow chart for preparing the thermal responsible microcapsules containing SHC. Prior to the 


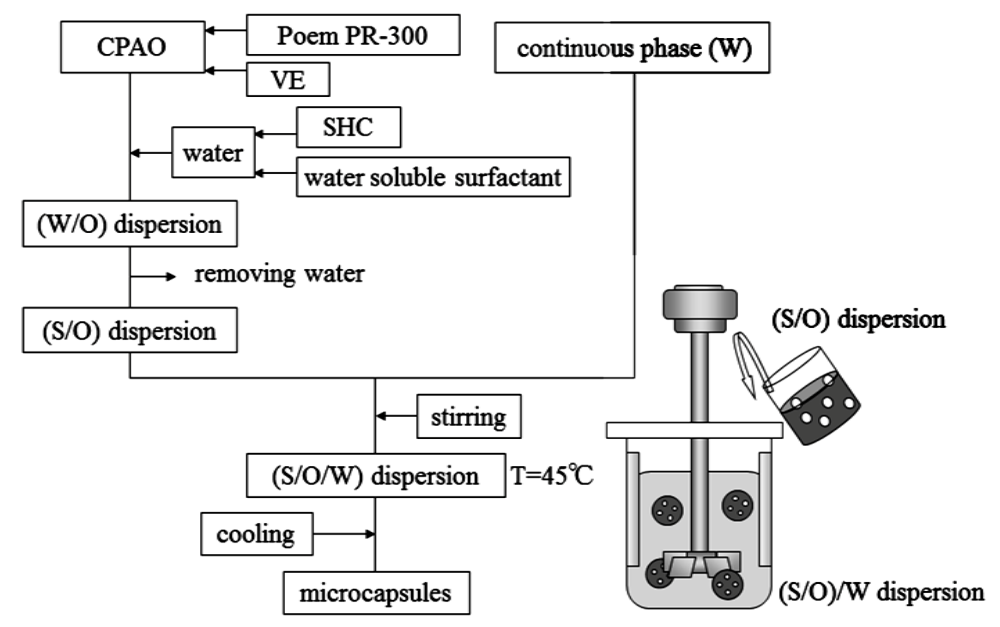

Figure 1. Flow chart for preparing microcapsules and schematic diagram of experimental apparatus.

microencapsulation, SHC was treated by the following method. Namely, SHC was dissolved once in distilled water dissolving the water soluble surfactant. Then, the aqueous solution of SHC was added into olefin wax dissolving the oil soluble surfactant and $\alpha$-tocopherol and then, stirred with the six bladed turbine impeller of 5.0 $\mathrm{cm}$ diameter to form the $(\mathrm{W} / \mathrm{O})$ dispersion.

After this operation, the water phase of the (W/O) dispersion was removed under reduced pressure and $45^{\circ} \mathrm{C}$ to form the (S/O) dispersion. The finer solid powder could be formed by this operation and stabilized with the water soluble surfactant. The (S/O) dispersion was added into the continuous phase and stirred with the six bladed turbine impeller of $5.0 \mathrm{~cm}$ diameter to form the $(\mathrm{S} / \mathrm{O}) / \mathrm{W}$ dispersion. The procedure stated just above was performed at $45^{\circ} \mathrm{C}$. Then, the $(\mathrm{S} / \mathrm{O}) / \mathrm{W}$ dispersion was cooled down to room temperature in order to solidify the olefin wax and to prepare the microcapsules.

In this fundamental experiment, the concentration of oil soluble surfactant and the water soluble surfactant species were changed. The experimental conditions used in this experiment are shown in Table 1, in which the experimental conditions and those parameters were determined by considering the results in previous studies [4]-[6]. Also, the dispersion ratios such as in the $(\mathrm{S} / \mathrm{O})$ dispersion, the $(\mathrm{W} / \mathrm{O})$ dispersion and $(\mathrm{S} / \mathrm{O} / \mathrm{W})$ dispersion were determined in order to keep the dispersion stable by refering the results [4]-[6].

\subsection{Characterization}

\subsubsection{Thermal Responsibility}

Thermal responsibility of microcapsules was measured by differential scanning calorimetry (DSC; Shimazu Co., Ltd., DSC-50, Kyoto, Japan) and by observing the change in the color of dye aqueous solution due to carbon dioxide generated on the basis of dissolution of SHC in the solution.

\subsubsection{Mean Diameter of Microcapsules}

The mean diameters of microcapsules were measured by particle size analyzer (SALD-3000; Shimazu Co., Ltd.).

\subsubsection{Observation of Microcapsules}

The microcapsules were observed by scanning electron microscope (SEM) (VE-9800, Keyence Corp. Osaka, Japan) and optical microscope (BH-2; OLYMPUS Co., Ltd., Tokyo, Japan).

\subsubsection{Microencapsulation Efficiency}

The microencapsulation efficiency(R) was estimated by Equation (1).

$$
\mathrm{R}(\%)=\frac{\text { weight of microencapsulated solid powder }}{\text { weight of solid powder in feed }} \times 100
$$


Table 1. Experimental conditions.

\begin{tabular}{cc}
\hline (S/O) dispersion & $2.0 \mathrm{~g}$ \\
\hline Solid powder (SHC) & $4.0 \mathrm{~g}$ \\
Olefin wax (CPAO) & $4.0 \mathrm{~g}$ \\
$\alpha$-tocopherol (VE) & Poem PR-300 \\
Surfactant & \\
Continuous phase & $100 \mathrm{~g}$ \\
Glycerin & $\mathrm{J}-0021, \mathrm{DL}-100$ \\
Surfactant & \\
Preparation of dispersion & $600 \mathrm{rpm}$ \\
Impeller speed & $5 \mathrm{~min}$ \\
Time & $45^{\circ} \mathrm{C}$ \\
Temperature & \\
Operating conditions & $\mathrm{C}_{\mathrm{o}}=1.0,3.0,5.0,7.0,10 \mathrm{wt} \%$ \\
Conc. of oil soluble surfactant & $\mathrm{CW}_{\mathrm{W}}=0,0.1,0.5 \mathrm{wt} \%$ \\
Conc. of water soluble surfactant & \\
\hline
\end{tabular}

Here, the weight of microencapsulated solid powder was measured from the change in weight obtained by TGA (DTG-50/50H; Shimazu Co., Ltd.).

\section{Results and Discussion}

\subsection{Effect of Concentration of Oil Soluble Surfactant on Thermal Responsibility of Shell Material}

In order to form the stable $(\mathrm{S} / \mathrm{O})$ dispersion and the stable $(\mathrm{S} / \mathrm{O}) / \mathrm{W}$ dispersion, the oil soluble surfactant of the higher concentration was dissolved in the shell material solution. So, it may be possible that the thermal responsibility of shell material is affected.

Figure 2 shows the effect of the concentration of oil soluble surfactant on the thermal responsibility of shell material. Here, the melting start temperature $\left(T_{m}\right)$ and the melting peak temperature $\left(T_{p}\right)$ were measured by DSC as an index of thermal responsibility of microcapsule shell. The melting start temperature $\left(T_{m}\right)$ and the melting peak temperature $\left(\mathrm{T}_{\mathrm{p}}\right)$ were not almost affected even by changing the concentration $\left(\mathrm{C}_{\mathrm{o}}\right)$ of oil soluble surfactant from 0 to $10 \mathrm{wt} \%$. From this result, it was confirmed that the thermal responsibility of shell material could be kept in spite of addition of oil soluble surfactant.

\subsection{Effect of Concentration of Oil Soluble Surfactant on Microcapsulation Efficiency and Mean Diameter}

Figure 3 shows the dependences of the microencapsulation efficiency $(R)$ and the mean diameter $\left(\mathrm{d}_{\mathrm{p}}\right)$ of microcapsules on the concentration of oil soluble surfactant $\left(\mathrm{C}_{0}\right)$. The mean diameters and the microencapsulation efficiency increased from $100 \mu \mathrm{m}$ and $24 \%$ at $\mathrm{C}_{\mathrm{o}}=0 \mathrm{wt} \%$ to $220 \mu \mathrm{m}$ and $52 \%$ at $\mathrm{C}_{\mathrm{o}}=10 \mathrm{wt} \%$, respectively. In general, it is well known that the higher the viscosity of dispersed phase becomes, the larger the diameters of dispersed droplets become because of increase in viscous force against destructive force acted on the droplet. Namely, when the viscous force due to the viscosity of dispersed phase becomes larger than the destructive force acted on the droplet due to turbulent energy, the droplets are not broken easily and the diameters of droplets become larger in the turbulent field [14]. As the viscosity $\left(\mu_{\mathrm{d}}\right)$ of dispersed oil phase increased by addition of the oil soluble surfactant as shown in Figure 4, the mean diameters of dispersed droplets, as a result, the mean diameters of the microcapsules may increase. It is well known that increasing the diameters of microcapsules 


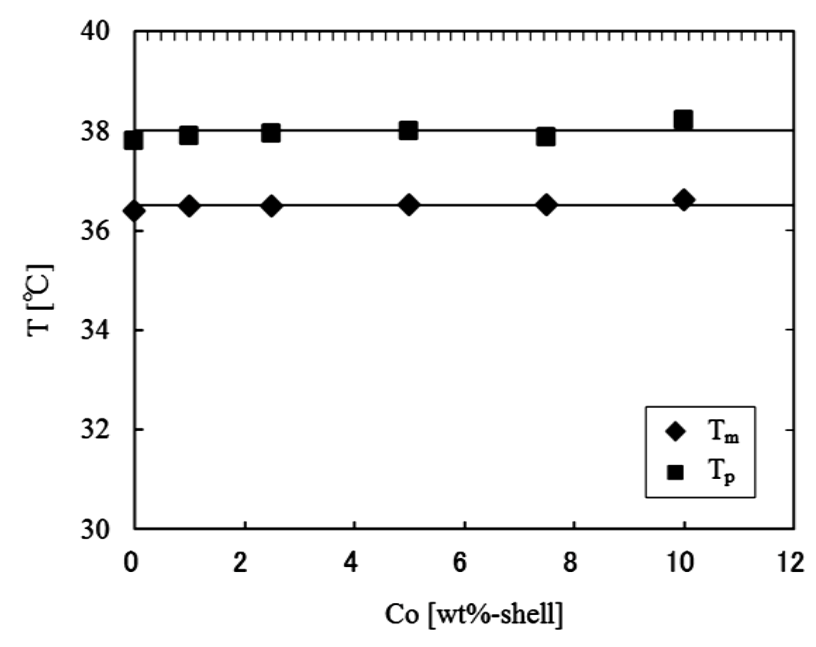

Figure 2. Effect of concentration of oil soluble surfactant on thermal responsibility $\left(T_{m}, T_{p}\right)$.

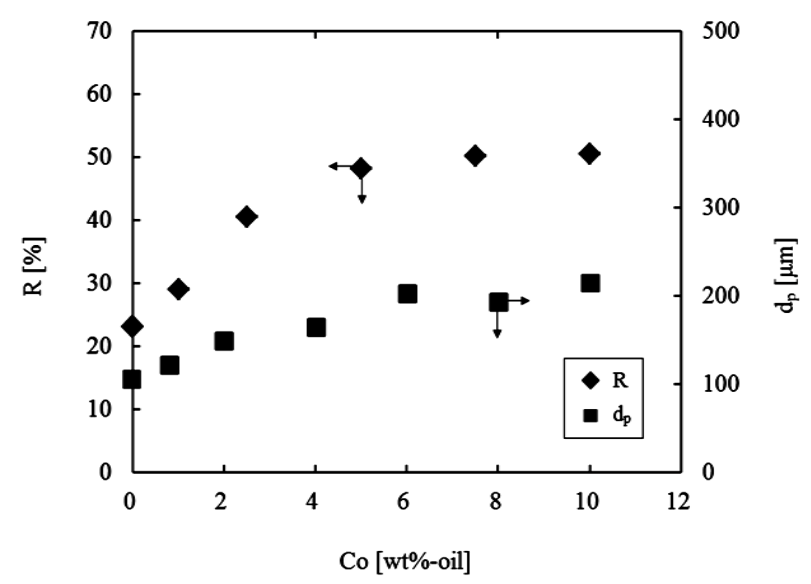

Figure 3. Dependences of mean diameters of microcapsules and the microencapsulation efficiency on concentration of oil soluble surfactant.

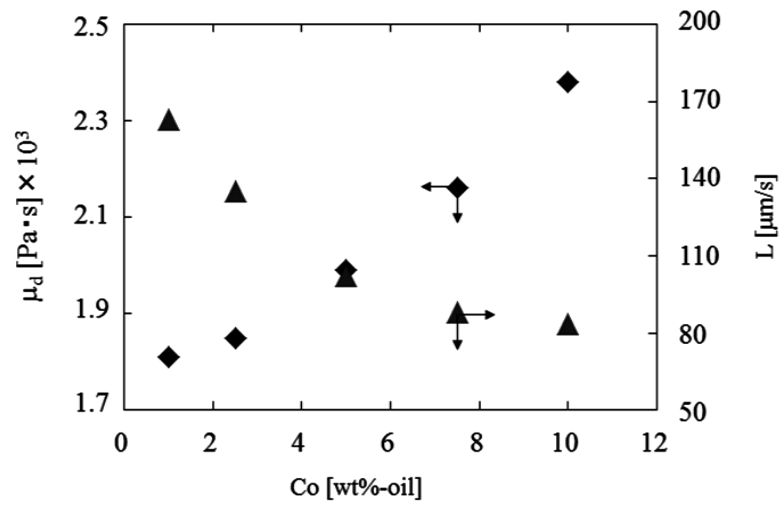

Figure 4. Dependences of viscosity of oil phase and the sedimentation velocity on concentration of oil soluble surfactant.

contributes to increasing the microencapsulation efficiency. Also, the solid powder in the oil phase can be stabilized by increasing the viscosity of oil phase as shown in Figure 4, because the sedimentation velocity (L) of a 
solid powder particle is decreased with the viscosity of oil phase. Here, the sedimentation velocity $(\mathrm{L})$ is estimated by the Stokes sedimentation velocity equation defined as the following Equation (2).

$$
\mathrm{L}=\mathrm{D}_{\mathrm{p}}\left(\rho_{\mathrm{p}}-\rho_{\mathrm{c}}\right) \mathrm{g} / 18 \mu_{\mathrm{c}}
$$

where $\mathrm{D}_{\mathrm{p}}, \rho_{\mathrm{p}}, \rho_{\mathrm{c}}, \mathrm{g}, \mu_{\mathrm{c}}$ are the particle diameter, the particle density, the continuous phase density, gravitational acceleration and the continuous phase viscosity, respectively.

As a result, the microencapsulation efficiency could be increased with the concentration of oil soluble surfactant.

\subsection{Effect of Treation of Solid Powder}

As the microencapsulation efficiency is low as shown in Figure 3, SHC was treated in order to increase the content.

Figure 5 shows the effect of water soluble surfactant species on the mean sizes $\left(\mathrm{d}_{\mathrm{s}}\right)$ and standard deviation $(\sigma)$ of the diameter distribution of SHC treated by changing the concentration $\left(\mathrm{C}_{\mathrm{W}}\right)$ of water soluble surfactant in the inner water phase. From these figures, it was found that SHC treated by DL-100 become smaller and more uniform than those treated by J-0021. Also, SHC treated by DL-100 become considerably smaller than untreated SHC as shown in Figure 6, where the untreated powder means SHC as received.

Figure 7 shows the dependences of the mean diameters $\left(\mathrm{d}_{\mathrm{p}}\right)$ of microcapsules and the sedimentation velocity (L) of SHC in the oil phase $\left(\mathrm{C}_{\mathrm{o}}=0 \mathrm{wt} \%\right)$ on the concentration $\left(\mathrm{C}_{\mathrm{W}}\right)$ of water soluble surfactants.

From these figures, it was found that the mean diameters of microcapsules were kept almost constant $\left(d_{p}=\right.$ $100 \mu \mathrm{m})$ even by changing the concentrations of the water soluble surfactants. As the water soluble surfactant may absorb preferentially on the interface between the inner water and the oil phase because of larger interfacial area, the interfacial tension between the continuous phase and the oil phase may not be affected. Accordingly, the diameters of oil droplet, as a result, the diameters of the microcapsules may be kept content. Also, the sedimentation velocities (L) were smaller than $10 \mu \mathrm{m} / \mathrm{s}$. Especially, the sedimentation velocities of SHC treated by DL-100 were considerably smaller compared with those $(\mathrm{L}=80-170 \mu \mathrm{m} / \mathrm{s})$ for untreated SHC as shown in Figure 4. Furthermore, the stability of SHC treated may be considered due to the wrapping stabilizing effect due to the hydrophilic group of molecule of water soluble surfactant in the oil droplets [15]-[17].

Figure 8 shows the dependence of microencapsulation efficiency (R) on the concentration of water soluble
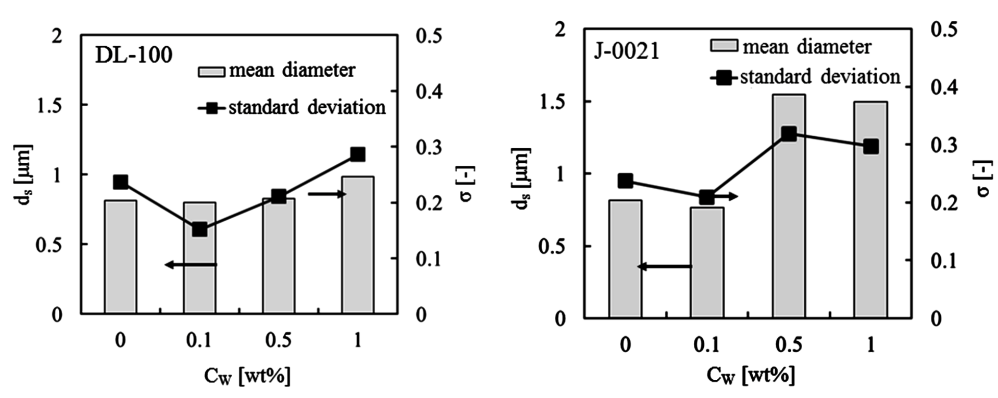

Figure 5. Effect of concentration of water soluble surfactant species on mean diameters and standard deviation of SHC.

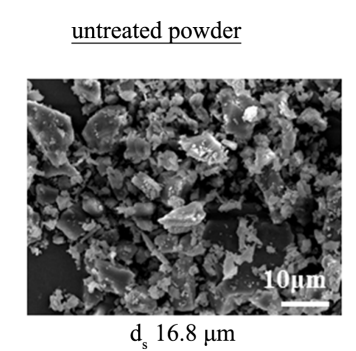

$\begin{array}{lll}\mathrm{s} & 0.517\end{array}$

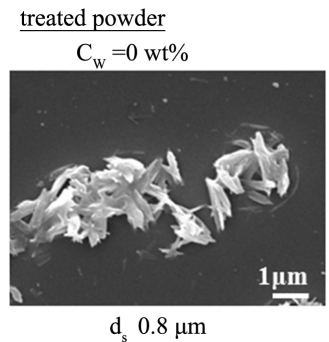

o 0.23

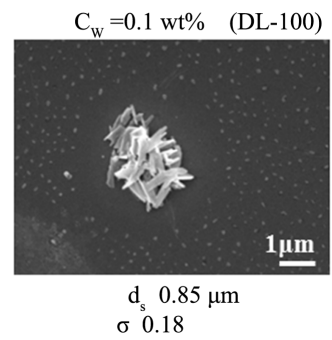

Figure 6. SEM photographs of SHC with and without treation. 

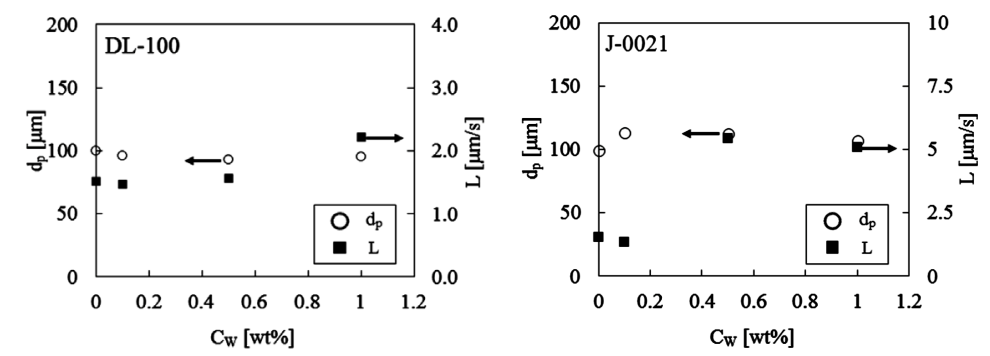

Co $=0 \mathrm{wt} \%$

Figure 7. Dependences of mean diameters of microcapsules and the sedimentation velocity on concentration of water soluble surfactant species.

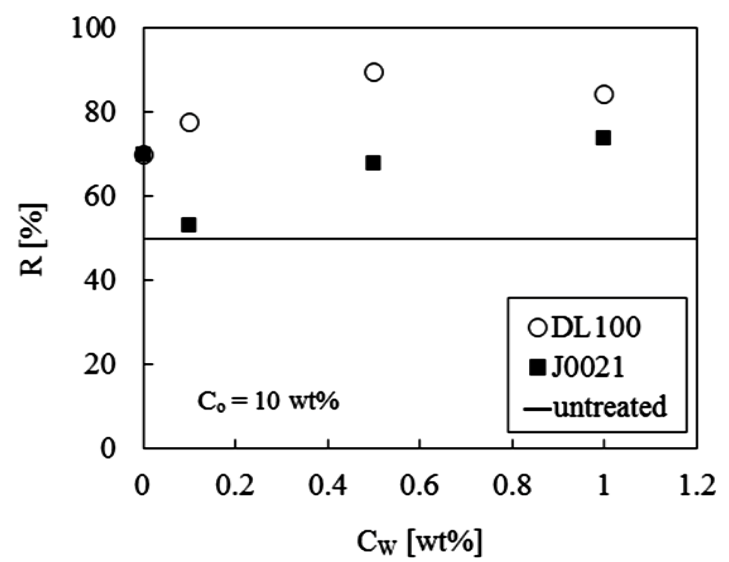

Figure 8. Dependence of microencapsulation efficiency on concentration of water soluble surfactant species.

surfactant together with the results for the untreated SHC. The microencapsulation efficiency could be considerably increased by the treation of SHC, especially from $79 \%$ to $90 \%$ by the treation with DL- 100 .

By the way, the mean diameters of microcapsules, the microencapsulation efficiency and the sedimentation velocities at $\mathrm{C}_{\mathrm{o}}=10 \mathrm{wt} \%$ for the untreated SHC were $220 \mu \mathrm{m}, 52.0 \%, 80 \mu \mathrm{m} / \mathrm{s}$ as shown in Figure 3 and Figure 4 , respectively.

\subsection{Thermal Responsibility of Microcapsules and Carbon Dioxide Generation}

Figure 9 shows the results observing the thermal responsibility of microcapsules and carbon dioxide generation. The microcapsules slightly melted at $36^{\circ} \mathrm{C}$ as shown in Figure 9(a). The color of the dye aqueous solution at $\mathrm{pH}$ 1.7 and 4.0 was orange at $30^{\circ} \mathrm{C}$ comparing the color of each $\mathrm{pH}$ aqueous solution, because the microcapsules were not melted and SHC was not released as yet. However, the color changed from orange at $30^{\circ} \mathrm{C}$ to blue at $36^{\circ} \mathrm{C}$ and $40^{\circ} \mathrm{C}$. This means that the microcapsules were melted in the acid solution at $36^{\circ} \mathrm{C}$ and $40^{\circ} \mathrm{C}$, released SHC and generated carbon dioxide to change the dye aqueous solution to the alkaline solution.

From these results, it was confirmed that the microcapsules showed the thermal responsibility and could generate carbon dioxide.

The microencapsulation procedure developed in this study may be applied to microencapsulate the various water soluble solid powders generating the desired gas instead of microencapsulating directly the gaseous core materials.

\section{Conclusions}

The microcapsules containing sodium hydrogen carbonate were prepared with olefin wax by using the melting dispersion cooling method instead of microencapsulating directly carbon dioxide. The following fundamental results were obtained. 


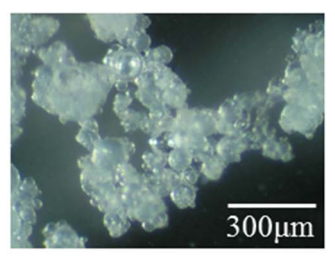

at $30^{\circ} \mathrm{C}$

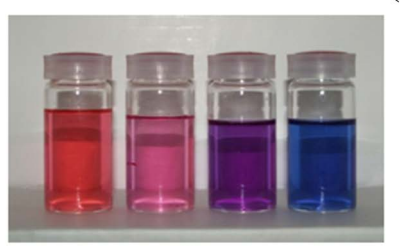

$\mathrm{pH} \quad 1.7, \quad 4.0, \quad 6.9, \quad 9.0$

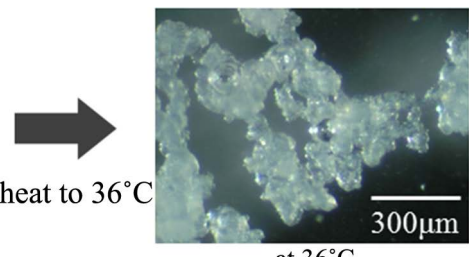

(a)

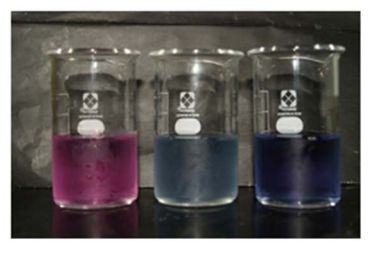

(b) $30^{\circ} \mathrm{C} \quad 36^{\circ} \mathrm{C} \quad 40^{\circ} \mathrm{C}$

Figure 9. Thermal responsibility of microcapsules and carbon dioxide generation.

1) The mean diameters and the microencapsulation efficiency of microcapsules increased with the concentration of oil soluble surfactant.

2) The microencapsulation efficiency could be considerably increased by dissolving sodium hydrogen carbonate together with the water soluble surfactant in inner water and by making solid powder smaller.

3) The microcapsules were melted and broken at the temperature higher than $36^{\circ} \mathrm{C}$, released sodium hydrogen carbonate and generated carbon dioxide.

4) It may be expected that the microencapsulation procedure developed in this study could be applied to microencapsulate solid powder instead of microencapsulating directly the gaseous core materials with applicability to cosmetic materials.

\section{References}

[1] Kondo, T. (1967) Saishin Maikurokapseruka Gijutsu (Microencapsulation Technique). TES, Tokyo.

[2] Tanaka, M. (2008) Key Point of Preparation of Nano/Microcapsules. Techno System Publishing Co. Ltd., Tokyo.

[3] Koishi, M., Eto, K. and Higure, H. (2005) (Preparation + Utilization) Microcapsules, Kogyo Chosakai, Tokyo.

[4] Takahashi, M., Taguchi, Y. and Tanaka, M. (2008) Microencapsulation of Hydrophilic Solid Powder as Fire Retardant Agent with Epoxy Resin by Droplet Coalescence Method. Journal of Applied Polymer Science, 110, 1671-1676. http://dx.doi.org/10.1002/app.28211

[5] Takahashi, M., Taguchi, Y. and Tanaka, M. (2009) Microencapsulation of Hydrophilic Solid Powder as a Fire Retardant by the Method of in Situ Gelation in Droplets Using a Non-Aqueous Solvent as the Continuous Phase. Polymers \& Polymer Composites, 17, 83-90.

[6] Takahashi, M., Taguchi, Y. and Tanaka, M. (2010) Microencapsulation of Hydrophilic Solid Powder as a Flame Retardant with Epoxy Resin by Using Interfacial Reaction Method. Polymers for Advanced Technologies, 21, $224-228$.

[7] Yuan, W., Ren, T., Wu, F., Zhao, H. and Jin, T. (2010) A Novel Preparation Method for Microspheres by Glycerol Modified Solid-in-Oil-in-Water Multi-Emulsion. Polymers for Advanced Technologies, 21, 371-376. http://dx.doi.org/10.1002/pat.1438

[8] Xia, H., Zhang, Y., Peng, J., Fang, Y. and Gu, Z. (2006) Preparation of Silver-Poly (Acrylamide-co-Methacrylic Acid) Composite Microspheres with Patterned Surface Structures. Colloid and Polymer Science, 284, 1221-1228. http://dx.doi.org/10.1007/s00396-006-1472-0

[9] Gao, Q., Wang, C., Liu, H., Wang, C., Liu, X. and Tong, Z. (2009) Suspension Polymerization Based on Inverse Pickering Emulsion Droplets for Thermos-Sensitive Hybrid Microcapsules with Tunable Supracolloidal Structures. Polymer, 50, 2587-2594. http://dx.doi.org/10.1016/j.polymer.2009.03.049

[10] Schuch, A., Wrenger, J. and Schuchmann, H.P. (2014) Production of W/O/W Double Emulsions. Part II: Influence of Emulsification Device on Release of Water by Coalescence. Colloids and Surfaces A: Physicochemical and Engineering Aspects, 461, 344-351. http://dx.doi.org/10.1016/j.colsurfa.2013.11.044

[11] Taguchi, Y., Aoki, M. and Tanaka, M. (2014) Preparation of Microcapsules Containing Triple Core Materials with In- 
terfacial Condensation Reaction. Journal of Cosmetics, Dermatological Sciences and Applications, 4, 275-283. http://dx.doi.org/10.4236/jcdsa.2014.44037

[12] Norman, J.N., Macintyre, J., Shearer, J.R., Craigen, I.M. and Smith, G. (1970) Effect of Carbon Dioxide on Renal Blood Flow. American Journal of Physiology, 219, 672-676.

[13] Xu, F., Uh, J., Brier, M.R., Hart Jr., J., Yezhuvath, U.S., Gu, H., Yang, Y. and Lu, H. (2011) The Influence of Carbon Dioxide on Brain Activity and Metabolism in Conscious Humans. Journal of Cerebral Blood Flow \& Metabolism, 31, 58-67. http://dx.doi.org/10.1038/jcbfm.2010.153

[14] Mizoguchi, K., O’Shima, E. and Inoue, H. (1974) Characteristics of Dispersion of Viscous Liquid in Agitated Vessel. Kagaku Kogaku, 38, 244-249. http://dx.doi.org/10.1252/kakoronbunshu1953.38.244

[15] Kobayashi, S., Taguchi, Y. and Tanaka, M. (2005) Preparation of Nanospheres Containing Dye by Mini Emulsion Polymerization. Journal of the Japan Society of Colour Material, 78, 260-264. http://dx.doi.org/10.4011/shikizai1937.78.260

[16] Erdem, B., Sudol, E.D., Dimonie, V.L. and El-Aasser, M.S. (2000) Encapsulation of Inorganic Particles via Miniemulsion Polymerization. I. Dispersion of Titanium Dioxide Particles in Organic Media Using OLOA 370 as Stabilizer. Journal of Polymer Science Part A: Polymer Chemistry, 38, 4419-4430. http://dx.doi.org/10.1002/1099-0518(20001215)38:24<4419::AID-POLA110>3.0.CO;2-X

[17] Erdem, B., Sudol, E.D., Dimonie, V.L. and El-Aasser, M.S. (2000) Encapsulation of Inorganic Particles via Miniemulsion Polymerization. III. Characterization of Encapsulation. Journal of Polymer Science Part A: Polymer Chemistry, 38, 4441-4450. http://dx.doi.org/10.1002/1099-0518(20001215)38:24<4441::AID-POLA130>3.0.CO;2-U 